\title{
Exploration and Analysis of Occupational Stress of the Primary and Middle School Teachers
}

\author{
Bai Xiujie \\ School of Education Science, Baicheng Normal University, Baicheng 137000, China \\ email:805137560@qq.com,*corresponding author
}

Keywords: mental health, occupational stress, primary and middle school teachers

\begin{abstract}
The teachers' mental health directly or indirectly affects the students' personality and mental health and is the key to the success of students' education, and yet the occupational stress of primary and middle school teachers has a great effect on their mental health. This paper discusses mainly the importance of primary and middle school teachers' mental health, and explores the reasons for the formation of occupational stress, hoping to be useful for the work of relevant education and teaching staff.
\end{abstract}

\section{Introduction}

At present, with the development of society, that the competition is becoming more and more intense have made the students' psychological pressure and psychological problems constantly increase. People have had a profound understanding of the importance of mental health education. The Ministry of education in the file, " some opinions on developing mental health education in primary and secondary schools", points out that primary and secondary schools should gradually create conditions to carry out mental health education according to their actual situation from the beginning of the autumn of 2000 in small and medium sized city. That requires teachers to do the work of students' psychological health well and play the role of the students' psychological maintenance well, but need pay more attention to teachers' psychological health education which is because the hope of revitalizing the nation depends on education, the hope of revitalizing education depends on teachers. School is a whole composed of students and teachers, teachers are the key to school education. The teacher is not only the transfer of the human culture, the leaders of the collective activities, agents of parents and students, but also the students' intimate friends and shaping of the students' mind, that is to say the teacher is not only influencer of students' mental health and disseminator of knowledge of students' personality, but also the implementer of mental health education. Therefore, teachers' personality and mental health directly or indirectly affect the students' personality and mental health and also affects the student's psychology and behavior, at the same time for the teachers' personal success or failure of the work it also play a significant role.

\section{The Importance of the Primary and Middle School Teachers Mental Health}

Teachers' Mental Health is the Guarantee of Teachers' Health. A healthy spirit conservation and health body have become a consensus of modern people. If a person in bad mood or mental state for a long time, such as worry, tension, anxiety, depression and so on, his physiological mechanism, endocrine mechanism and immune mechanism will be affected, leading to physiological unhealthy even the disease. On the contrary, psychological health will effectively enhance the function of the body and promote physical health.

Healthy Psychology is A Prerequisite for a Teacher's Work Enthusiasm and Creativity. A person's mental state will directly affect the working performance of the individual. When people feel irritable and anxious, it is difficult to do anything and no more efficiency at all. Only the teachers are in a positive and healthy psychological state, can they give full play to their initiative and creativity, so as to achieve satisfactory results. Moreover, the bad mood and emotion will directly inhibit passion and enthusiasm of teachers work, even erode their will and ambition. 
The Psychological Health of Teachers is the Guarantee of the Healthy Growth of Students. A large number of studies show that the level of mental health of teachers directly affects the development of students' mental health, social character and personality traits. The reasons are as follows.

Only teachers of the positive psychological health, can they create a harmonious and warm atmosphere in the classroom, so that make students feel happy. On the contrary, their tension, irritability, depression often make classroom form a atmosphere of tension and depression that make students jittery.

When the teachers in the ill-health mental status, their inappropriate education behavior often hurt the students' self-esteem, self-confidence, and enable students to excessive anxiety, depression or resist, and seriously affect the healthy development of students' personality and emotion. Solomon professor said: "in the individual personality development, the influence of teachers rank only second to the parents. If a child has a sweet family, enjoy the love of parents and get a physical and mental health teachers, he is very happy. On the contrary, if he can't get enough care and love from my parents, get the unprovoked distress of emotionally unstable teachers, will cause a lot of the problem of physical and mental development "

The teacher's occupation is a special one, is a occupation of life touched by life, water soul with soul, as Jaspers said: "education means that a tree shakes another tree, a cloud pushes another cloud, a soul awakens another soul." Obviously, only teachers of psychological health, can they cultivate students' mental health.

Teacher's Mental Health is Directly Related to the Teacher's Ability to Have a Healthy and Happy Life. Teachers' mental health directly affect their interpersonal attitudes and behavior, it not only affect the teacher-student relationship and the relationship between colleagues, but also affect the family. Many teachers have a very good performance over their students in the work, but after the work they are often not patience and consciously put negative emotions to take home, not good attitude for family, that directly affect the marital relationship, parent-child relationship, family atmosphere and quality.

\section{Analysis on the Occupational Stress of Primary and Middle School Teachers}

Teachers are a special profession, teachers' occupational stress is the main factor that affects teachers' mental health. The so-called occupational stress refers to the pressure of physical and psychological load and negative emotion, such as anger, anxiety, depression or loss in the teaching practice of teachers .Teachers in primary and secondary schools are the main body of teachers, and the sources of their occupational stress are various.

Primary and Middle School Teachers are Congenitally Deficient, Acquired Disorders and the Teaching Level Can Not Meet the Needs of Teaching. Former State Education Commission Planning Secretary Zhou Beilong ,his definition of primary and middle school teachers is "the primary and middle school teachers hard to support " in Interpretation of Chinese Education. In primary and middle school, the existing staff is 10 million 690 thousand, including 8 million 920 thousand full-time teachers, most of them are struggling with the basic education of our country building in poor condition. The performance is as follows:

The education level of primary and middle school teachers is too low. We cancel normal school in 2000, but the training of primary school teachers mostly depends on the normal school students. They lack of high school education, so they can't meet the need of teaching from the breadth and depth of knowledge.

Even at the current low standards, primary school teachers now graduating from normal school above is only about 70\%, plus the high school level is nearly $83 \%$, and junior high school teachers in the pass rate is only 56\%. Education exists in the use of the phenomenon of talent raising.

According to the characteristics of education, the requirements of the best Chinese peers (at least $1 / 3$ ) in the teacher occupation, and China's education does not have enough appeal, the reality is far from this ideal state.

Because of the poor basic education, and the weakness of teacher education, many teachers can 
not reach the corresponding degree.

Teachers' ability to grasp their own work is the root reason of teachers' occupational stress. The basic education curriculum reform put forward new requirements of teachers' knowledge structure, way of thinking, teaching ability and teaching methods. Many teachers often feel frustration and failure, feel the heavy pressure due to the lack of their own quality to meet the need of the reform work.

Social and Cultural Changes Leading to the Psychological Pressure of Teachers. The dramatic change of culture has a great impact on people's psychological life, Tolov mentioned this phenomenon as" culture shock "in " future shock ",that people bear too much change after stressful, confused and disoriented, at a loss phenomenon in a very short period of time. Robert Nisbo's research shows that when the dramatic social changes cannot be personal control or imposed by the outside world , individual will generate pressure, otherwise the individual lack of control ability and prediction ability, whose pressure is more intense.

Modern people experience the rapid change of modern society in the way of compression, and the sharp contrast brings great pressure to all the Chinese people. Reflected the concept of new curriculum reform in education requires teachers to transfer from the imparting knowledge to the developers of intellectual resources, from education manager to learning facilitator. In order to meet the needs of the students, teachers have to constantly adapt to the cultural transformation, rapid learning and thinking of new culture, otherwise, in the process of transformation is full of pain and conflict, many teachers said with deep feeling: "Teaching for so many years, suddenly we don't know how to teach, and students will not get along."

The Social Cognition of Teachers' Profession Leads to the Teachers' Psychological Pressure. The traditional view is that education is a kind of lofty social commonweal career as the cause of "educating people", so teachers should not pursue individual interests. In order to balance the interests of teachers and teachers, people are not completely excluded from the moral value, but it is still a heavy and light, heavy groups and individual interests, therefore in the interests and moral expectations, people tend to emphasize the teachers' labor particularity or noble but not too concerned about the teachers' occupation as a "general" or "universal", that of teachers' moral expectations unlimited upgrade. Many teachers just give instead of asking to enjoy, but the teachers are social men, family men, they are the main source of the main members and family income families, facing the basic survival and improve the living pressure, the teacher occupation itself more pressure, more special, the teachers' psychological problems are more prominent.

The Burden of Education and Teaching is too Heavy, and the Autonomy of Teaching is Small. At present, teachers bear the heavy teaching tasks, and many teachers work overload, the survey shows: more than $50 \%$ of the teachers weekly lectures in more than $15,45 \%$ of the teachers lectures in more than 18,teacher's daily working hours is too long. A survey has suggested that the average working hours of elementary and middle school teachers in China is 9.67 hours, compared with 8 hours for 1.67 hours. In fact, the characteristics of the teacher's career has been determined that the actual working hours of the teachers can not only be measured by 8 hours, and many of their invisible labor pay is not measured.

Another manifestation of the heavy burden of teaching is the amount of teaching class is too large, the number of students primary and secondary schools in the city is more than 60 , mostly more than 80 students, resulting in the amount of correction, a substantial increase in workload.

Third performance of the teaching burden of the teachers is more administrative affairs, political learning, business learning, legal work, deal with the higher examination. If every activity can make teachers improve, teachers will have a sense of achievement, but all our activities just wasting time that doesn't solve any problems, the teacher is very offensive, thereby increasing the psychological burden.

An Unprecedented Social Demand and Competition Leads to Teachers' Psychological Pressure. With the development of society, people pay more and more attention to education, the expectation of society and parents to school education is higher and higher. As the creator of the good future of the students, the gap between the role of expectation and practice of teachers has 
become one of the most vulnerable areas of the field of condemnation.

In today's society, competition is fierce, teachers' living conditions are becoming more and more difficult, and the voice of teacher specialization is more and more high. Teachers face evaluation, appointment, winning the prize in the competition, competition provincial backbone teachers, striving to become a excellent teacher, otherwise they are in danger of being abandoned by occupation. More important, this change is to a degree of coercion, lack of individual motivation, therefore, an endless stream of educational reform for many teachers, not the gospel, but brought endless pressure.

New Characteristics of Educational Objects Lead to the Psychological Pressure of Teacher. Today, compared with the previous education, there has been a big change, the only child has become the subject of education, the proportion of children of single parent families is significantly increased. As there are more channels to obtain information, the influence of society is gradually infiltrated into all aspects of children's life, which to a certain extent weakened the role of learning and education. The new features of the object of education has brought new challenges to teachers occupation, if the primary and secondary school teachers still have a copy of the labor, and impart knowledge with the traditional way, but not changes teaching strategy flexibly according to the change of the educational object, that inevitably lead to the teacher's survival.

Careful Handling of Personnel, so that Teachers Feel Pressure. The teacher is not only the so-called counterparts, but also the so-called literati, so since ancient times, the intellectuals who abuse is very obvious on teachers, resulting in the formation of such as petty, jealous, self proclaimed higher psychological. In school, when you are in the lead, someone is jealous, and when you are behind, someone looked down upon you. Among the intellectuals have opinions, often like to say bad words behind, the more serious the bad mentality of teachers.

As the school leaders, their attitude is the most subtle, on the one hand, they hope the teachers work hard , have significant achievements, but they are afraid of some teachers too prominent achievements; on the other hand, they hope that teachers have high level degree, welcomed by students, but they don't want to see some teachers too rash, covered the main high power. This also caused the psychological pressure of teachers.

Therefore, primary and secondary school teachers are facing unprecedented pressure. Attention to their physical and mental health is the guarantee of the healthy growth of children and adolescents, and it is the duty of society.

\section{References}

[1] DENG Yuan-ping, LUO Xiao. Research on the Relationship between Teachers' Occupational Stress, Social Support and Mental Health-Illustrated by the Case of Primary and Secondary School Teachers[J],Journal of Jimei University,2011,12(1):44-48.

[2]WANG Pei, ZHANG Guo-li. The status investigation of primary and junior high school teachers' occupation pressure and its enlighten[J],EDUCATION EXPLORATION,2005,(10):116-117.

[3]MA Ya-ju.Factors of Occupational Stress of Primary and Middle School Teacher and Self-adjustment[J],VALUE ENGINEERING,2011,30(13):219-220.

[4]MA Juan ,CHEN Xu, The Effect of Occupational Stress on The Class Interaction of Middle and Primary School Teachers[J],CHINESE MENTAL HEALTH JOURNAL,2007,21(6):404-406.

[5]Lv Zouqin, Ling Hui, Relationship among Stress, Social Support and Job Burnout of Primary/Middle School Teachers[J],China Journal of Health Psychology,2014,(9):1344-1348. 